\title{
Lead Fracture as a Cause of Pacemaker Failure: A Case Report
}

\author{
AAS MAJUMDER ${ }^{1}$, AW CHOWDHURY $^{2}$, AEM MAZHARUL ISLAM $^{3}$, MA MUTTALIB $^{4}$, MM ALAM $^{5}$
}

(University Heart Journal 2007; 3 : 87-89)

\section{Introduction}

Cardiac pacing is a rapidly advancing and ever changing specialty. Pacemakers were first introduced in 1950s ${ }^{1}$. Since then over the last 5 decades cardiac pacing has undergone tremendous growth. In Bangladesh, pacemakers are being implanted since $1980 \mathrm{~s}^{2}$. The number of pacemaker implanted per year is increasing rapidly.

As with any interventional procedure, there are many potential complications of pacemaker insertion. Complications may arise from lead insertion related technique, lead itself, or pocket for generator. Besides this, pacemaker system malfunction due to pacemaker circuitry failure or to lead dysfunction may arise.

Five groups of true malfunctions are recognized: power source failure, output or timing circuit failure, pacemakerpatient electrical short circuit and pulse generator rendered inoperative in a magnetic field (e.g. MRI).

Among the above malfunctions, incomplete pacemaker patient electrical circuit is uncommon but not rare. An electrode lead system fracture with complete discontinuity will result in an inoperative pacemaker system. Insulation break, lead fracture can cause failure to capture, over sensing and under sensing. In this case report we are describing an elderly patient with permanent pacemaker, implanted 4 years back, diagnosed as lead fracture, the patient was managed by implantation of a new lead.

\section{Case report}

A 68 years old pensioner, hypertensive man on permanent pacemaker for the last 4 years, was admitted in National Institute of Cardiovascular Diseases (NICVD) with the complaints of intermittent loss of consciousness while on standing for last 1 month. Each episode persisted for 1-2 minutes followed by spontaneous recovery with no residual neurological deficit. He had no chest pain, palpitation, shortness of breath, convulsion, tongue biting, spontaneous micturition or defaecation before or during the attack. He checked his PPM status 3 month before.

1. Professor Abdullah Al Shafi Majumder, Dept. of Cardiology, NICVD

2. Dr. Abdul Wadud Chowdhury, Dept. of Cardiology, NICVD

3. Dr. A.E.M. Mazharul Islam, Dept. of Cardiology, NICVD

4. Dr. Md. Abdul Muttalib, Dept. of Cardiology, NICVD

5. Dr. Mahinoor Mortuja Alam, Dept. of Cardiology, NICVD

Address of Correspondence to: Dr. Abdul Wadud Chowdhury, Dept. of Cardiology, NICVD, Dhaka

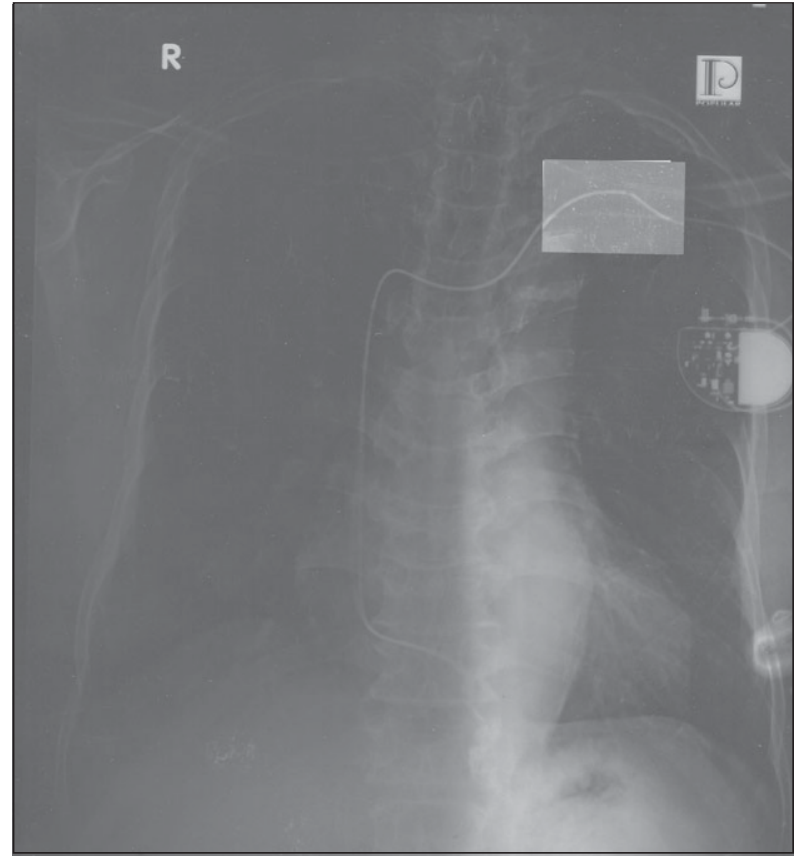

On examination he was well looking, average body built with good nutritional status, had a regular pulse rate of 60 bpm, normal volume and character, bilaterally symmetrical, no radio femoral delay, and carotid bruit. BP was 130/80 $\mathrm{mm} \mathrm{Hg}$ and no postural hypotension. A pacemaker generator was palpable in the left infraclavicular region with healthy overlying tissue. 
Resting ECG showed pacing spike without capture .Chest X-ray revealed pacemaker in situ and lead with the tip in the right ventricle. A tiny fracture of lead was noted at the level of mid part of left clavicle .Echocardiography showed tip of the lead in the right ventricular apex and good left ventricular systolic function .On PPM status checking resistance was found low(276 ohm), lower than initial resistance $(660 \mathrm{ohm})$. Threshold was very higher $(3.0 \mathrm{v})$ than initial threshold $(0.6 \mathrm{v})$.

With above findings patients was diagnosed as having pacemaker malfunction due to insulation break of the lead .Later on, generator was removed from the pocket and the lead was tied with insulated cover. Through the subclavian puncture steroid eluting, bipolar, implantable, screw-in lead was introduced and placed at the right ventricular apex.

\section{Discussion}

The artificial pacemaker is an integrated, sophisticated system dependent on an intact electrical circuit for adequate function. The basic pacemaker system consists of a pulse generator connected to one or two leads attached to the heart. Almost all pacemakers use lithium iodide battery. Lithium iodide batteries can be hermetically sealed and are therefore resistant to corrosion. They also provide high-volumetric energy density. Pacemaker lead may be endocardial or epicardial. Endocardial leads are used in about $95 \%$ of implants, epicardial leads in only $5 \%$.

Leads are insulated conductor wires that deliver electrical impulses to the heart and return sensed electrical signals from the heart to the pulse generator. One end of the lead connects to the pulse generator and the other is in contact with cardiac tissue. A lead has 5 components; electrode, insulator, conductor, connector pin, and fixation system.

One of the most important components of any lead system is the insulation. The insulation prevents electrical shorting between the conductor coils within the lead, prevents stimulation of tissues other than the heart and allows smooth passage of the lead into the vein. The types of insulation commonly in use are silicone, polyurethane. The newest methodology to insulate leads is known as "coated coil" to each individual filament of the wire. The whole wire is then covered with a more standard insulator ${ }^{3}$.

The metal portion of the wire that carries electrical signals to and from the pacemaker and the electrode is the conductor coil. Most coils are made of multifilar (several strauds) components. This provides strength and flexibility as compared with a solid wire. Multiple conductor coils may be present in a lead.
The incidence of late complications following pacemaker implantation is low. The majorities are due to erosion, infection, and pacemaker malfunction ${ }^{4}$.Pacemaker system malfunction can be secondary to pacemaker circuitry failure or to lead dysfunction. The first step in evaluating pacemaker malfunction is to determine if the function of the device is truly abnormal or if one is seeing normal function of the device. With the advent of so many "special features" it is easy for even a person experienced with pacemakers to misinterpret the normal operation of a pacemaker. Major electro-cardiographic abnormalities of pacemaker system malfunction can broadly be categorized into the following: failure to capture, failure to output, under sensing and over sensing 5 .

As with any medical problem, the history is usually the key to determining the cause of a problem or at least to significantly narrowing the diagnostic options. If the problem occurs shortly after implant then lead dislodgement, insufficiently tightened set screws, or poor lead placement should be suspected as a cause rather than battery depletion or lead fracture. Conversely, an older device is more likely to be compromised by lead failure and battery depletion rather than lead dislodgement..

In general lead fractures tend to occur at stress areas, and three such points are identified. Probably the most common site is where the lead enters the vein, specially if there is a tight ligature is present. The next most important site is close to the pulse generator. A third site within the heart where the leads make a sharp turn. Lead conductor fractures also occurred following trauma and by sudden abduction and hyperextension of the shoulder.

When confronted with a patient with suspected pacemaker malfunction, the physician should follow a set investigate protocol. Any abnormal data should be repeated or confirmed by another method. The most important tests to establish pacemaker malfunction are electronic testing and ECG rhythm strip in both the synchronous and asynchronous modes.

The pacemaker rhythm strip confirms pacing at the time the ECG is taken. Electronic testing establishes the delivery of a normal stimulus artifact at the correct pulse repetition rate to the myocardium. The test should be performed in the asynchronous mode. Loss of capture requires a check of the pacing threshold and lead impedance. If

there is lead insulator break pacing threshold elevated and lead impedance decreased. In lead conductor fracture both pacing threshold and lead impedance are elevated. 
Of the approximately 400,000 to 500,000 permanent pacemaker leads implanted worldwide each year, $10 \%$ may eventually become potential candidates for removal and other procedures ${ }^{7}$. The treatment of conductor fracture or insulator break depends on the position of the break .Lead fracture next to the pulse generator can be treated by cutting the insulator at the site of the break, attaching a new connector, and reconnecting the pulse generator. Lead fractures at other sites may be difficult to treat. The preferred treatment is to implant a new lead ${ }^{8}$.

\section{References:}

1. Elmquist, R, Senning, A: Implantable pacemaker for the heart, In Smyth CN (ed): Medical Electronics, Proceedings of the second international conference on medical electronics, Paris, June 1959, London, Lliffe \& sons, 1960.

2. Haque, SA, Chowdhury, AW, Ali, MA, Ahmed, MU, Ali, M, 2003, ' Fourth Time Implantation of Permanent Pacemaker in a Patient With Complete Heart Block- A Rare Cardiovascular Event in the Country,' Bangladesh Heart Journal, vol. 18 ,no. 1 , pp. $72-5$.
3. Love, CJ: Handbook of Cardiac Pacing, $1^{\text {st }}$ ed , Georgetown, Texas, Landes Bioscience, 2006.

4. Harcombe, AA, Newell, S, Ludman, PF, Wistow, T, Schofield, PM, Stone, DL, Shapiro, LM, Cole,T, Petch, MC 1998,'Late Complications Following Permanent Pacemaker Implantation and Elective Unit Replacement', European Heart Journal, vol. 19, pp. 330 .

5. Vijayaraman, P, Ellenbogen, KA: Bradyarrythmias and Pacemakers In, Fuster, V, Alexander, RW, O'Rourke, RA, Roberts, R, King III, SB, Nash, IS, Prystowsky, EN (ed) :HURST'S The Heart, $11^{\text {th }}$ edition, New York, Mc Graw Hill, 2004.

6. Mond, HG: The Cardiac Pacemaker Function and Malfunction: $1^{\text {st }}$ ed, New York, Grunne \& Stratton, 1983.

7. Byrd, CL, Wilkoff, BL, Love, CJ, Sellers, TD, Turk, KT, Reeves, R, Young, R, Crevey, B, Kutalek, SP 1999,' Intravascular extraction of problematic or infected permanent pacemaker leads: 1994-1996. U.S. Extraction Database, Med Institute,' Pacing Clin Electrophysiol, vol. 22, no. 9, pp. 1348-57.

8. Hayes, DL: Pacemaker Complications, In, Furman,S, Hayes, DL, Holmes, DR, Jr (ed), A Practice of Cardiac Pacing, $3^{\text {rd }}$ ed, Mount Kisco ,Newyork,Futura,1993. 